\title{
La immigració francesa a Cervera segons els capítols matrimonials conservats a l'Arxiu Històric Comarcal de la ciutat (1501-1700)
}

\author{
Josep M. ${ }^{a}$ Llobet Portella *
}

\section{INTRODUCCIÓ}

Aquesta comunicació té com a objectiu exposar els resultats d'una recerca documental sobre la immigració de francesos a Cervera ${ }^{1}$ durant els segles XVI i XVII, desplaçament humà que es portà a terme, bàsicament, mitjançant la superació de la cadena muntanyenca dels Pirineus ${ }^{2}$.

* Profesor del Centro Asociado de Cervera (UNED). Comunicación presentada al Congreso Internacional de Historia de los Pirineos, Cervera, 1988.

La ciutat de Cervera, capital de la comarca de la Segarra, es troba situada a l'Altiplà Central de Catalunya. Sobre el seu emplaçament i característiques: Josep M. LLOBET I PORTELLA, "Cervera", Gran Geografia Comarcal de Catalunya, vol. 9, Barcelona, Fundació Enciclopèdia Catalana, 1983 , p. 44-65.

2 Mentre que el sector de la costa catalana gaudeix de diversos estudis sobre la immigració francesa -entre els més importants: Jaume COOINA, «La immigració francesa al delta del Llobregat, 1400-1700", XXV Assemblea Intercomarcal d'Estudiosos, El Prat del Llobregat, Centre d'Estudis Comarcals del Baix Llobregat i Amics del Prat, 1980, p. 226371; Enric MOREU-REY, Els immigrants francesos a Barcelona (segles XVI al XVIII). Barcelona, Institut d'Estudis Catalans, 1959; Jordi Nadal I Oller, i Emili Giralt i Raventós, La immigració francesa a Mataró durant el segle xvil, Mataró, Caixa d'Estalvis Laietana, 1966; J. NADAL, i E. GIRALT, La population catalane de 1553 à 1717. L'immigration française et les autres facteurs de son développement, París, SEVPEN, 1960; Francina SOLSONA, «Els francesos de Sant Pol de Mar al segle XVII", Annals de l'Institut d'Estudi Gironins, vol. XXV-II, (1981), p. 145-151, - la Catalunya interior no ha estat, tot i la realització d'alguns estudis valuosos - per exemple: Josep M. DE SOLÀ-MORALES, "La immigració francesa a Olot els segles XVI i XV|l», Miscel.lània històrica d'Olot i comarca, Olot, Ajuntament, 1983, p. 17-76-, tan afortunada. 
L'escassetat de fonts documentals ha fet que ens decidissem a utilitzar per al nostre estudi les sèries de registres de capítols matrimonials, pertanyents als notaris cerverins, contingudes dins el Fons Notarial de l'Arxiu Històric Comarcal de Cervera ${ }^{3}$. Aquests documents informen dels pactes establerts, poc temps abans del matrimoni, entre la família del nuvi i la de la núvia i són redactats en forma d'escriptura pública autoritzada per un notari.

A diferència dels registres parroquials de matrimonis - que a Cervera, d'aquell període, no s'han conservat-, els capitols matrimonials no formen una sèrie única i cronològicament seguida, la qual cosa fa que no puguem saber les pèrdues documentals que s'han produït durant el transcurs del temps. Però això no és un problema greu, ja que el que ens interessa principalment no és el nombre absolut de francesos que vivien, durant el periode estudiat, a la -aleshores - vila de Cervera i rodalies ni la quantitat d'aquells altres que s'hi trobaven de pas, sinó quans n'hi havia d'establerts en relació amb la resta dels habitants.

Una altra observació, encara. En els documents, els futurs marits ${ }^{4}$ són identificats de diferents maneres. Vegem alguns exemples: «Guilem Rubert, vidrier, del regne de Fransa, del loch de Martell, del bisbat de Tours", "Joan Mas, pagès, fill d'en Leonard Mas, pagès, de la vila de Cirlach, del bisbat de Tula, del regne de Fransa, y de na Joana, muller sua, vivints", "Arnau Llana, pagès, fill legítim y natural dels honorables en Joan Llana y d'en Franquina, de aquell muller, del lloc de Ponsà, del bisbat de Auix, del regne de França, defunts». A totes aquestes persones

3 La documentació consultada és la següent: 45 volums i lligalls dels notaris cerverins Pere Serra, Joan Montaner (major), Joan Codina, Pere Giscafrè, Jeroni Armengol, Jaume Mulet, Bartomeu Magre, Pere I Mir, Rafael Joan Montaner, Jeroni Porta, Pere Campardó, Andreu Benet Saurina, Jeroni Porta (menor), Rafael Renyer, Jacint Balcells, Francesc d'Assís Montaner, Joan Montaner (burgès), Jaume II Montornès, Rafael Joan Renyer i Josep Pomés i Mensa; 25 lligalls de notaris cerverins de nom desconegut (21 inclosos al grup «Cervera-Varis» i 4 a "Varis»). En total, doncs, 70 volums i lligalls. Sobre la distribució del Fons Notarial de l'Arxiu Històric Comarcal de Cervera: Montserrat Canela I Garayoa, i Montse Garrabou I Peres, Catàleg dels protocols de Cervera, Barcelona, Fundació Noguera, 1985.

${ }^{4}$ En aquest estudi només havem comptabilitzat els capítols matrimonials entre un francès i una catalana (o una francesa). No havem tingut en compte els casos, escassíssims, en què fou pactat el matrimoni entre un català i una francesa. Cal tenir present, també, que no tots els francesos o les noies amb les quals es casaven residien a la vila de Cervera. De tant en tant, algun membre de la parella consta com a habitant en alguna població de la rodalia. Això no vol dir que, una vegada casats, no poguessin establir la llar a Cervera. 
les tenim per immigrants francesos. Tant en el primer cas, on això consta d'una manera explícita, com en la resta, on considerem que se sobreentén ${ }^{5}$.

\section{RITME MIGRATORI}

Segons el quadre número 1, prop d'un $7 \%$ dels contractes matrimonials atorgats durant els segles XVI $\mathbf{i} X \mathrm{VII}$, permeten identificar el marit com a francès. A partir d'aquesta xifra podem establir tres períodes cronològics:

El primer aniria des del 1501 al 1550, amb xifres inferiors a la indicada. El segon comprendria des de l'any 1551 al 1630, amb quantitats superiors al tant per cent esmentat. El tercer abraçaria els decennis restants: des del 1631 al 1700; els matrimonis amb marit francès, llevat del decenni 1651-1660, haurien baixat per sota del $7 \%$ indicat.

La consideració iridividual de cada un d'aquests tres grups, ens permet una anàlisi més detallada del fenomen:

En el decenni 1501-1510, que ofereix un 2,66 \% de marits francesos, la fusió dels nouvinguts amb la societat cerverina és encara escassa, però durant els trenta anys següents la xifra ja s'ha elevat a més del doble. En arribar al decenni 1541-1550, un nou augment ja anuncia les xifres altes del període següent.

Efectivament, els vuit decennis compresos entre 1551 i 1630 , ens mostren uns percentatges que oscil.len al voltant del $10 \%$, encara que en els dos últims decennis d'aquest període ja s'insinua una baixa.

5 Aquests immigrants, després de la celebració matrimonial, es devien integrar ràpidament a la comunitat que els havia acollit; la catalanització del prenom i cognom facilità aquest procés. També era ràpida la pèrdua de la designació del lloc d'origen, així l'esmentat Guillem Rubert, que en els capitols matrimonials de l'any 1525 és designat com del regne de França, en altres establerts onze anys després -havem de suposar que enviduàconsta, simplement, como "Gilem Rubert, vidrier, de la vila de Cervera". 
A partir del 1631, la presència de marits francesos entre els matrimonis celebrats a Cervera, disminueix considerablement. Amb tot, fins a l'any 1680 encara és semblant o superior al primer decenni del segle XVI. A partir d'aquesta data i durant els dos últims decennis del període estudiat, el percentatge és ja insignificant: menys de l'u per cent.

Comentari apart mereix el decenni 1651-1660, amb més d'un $15 \%$ de marits francesos. Per una banda, la forta mortalitat produïda entre la població cerverina per les malalties i les violències de la guerra dels Segadors ${ }^{6}$ explicaria l'escassetat de casaments -o, almenys, de capítols matrimonials-, mentre que la retirada de les tropes franceses al final del conflicte potser pot fer pensar en la permanència d'algunes persones que no desitjarien tornar a la seva pàtria.

Una vegada havem analitzat el percentatge de marits francesos que mostren els capitols matrimonials, sembla lícit suposar que aquests augments o disminucions de nuvis francesos haurien de guardar una relació directa amb el nombre d'immigrants del regne de França que arribaven a Cervera.

Així, doncs, encara que no podem conèixer el nombre absolut dels francesos nouvinguts, ja que, a més dels que es casaven a Cervera $i$ rodälies, n'hi havia molts altres que no ho feien - hi havia, també, capellans francesos, dels quals ja hi ha constància a l'inici del període estudiat-, tots els quals surten contínuament en la documentació de l'època, sí que el percentatge esmentat ens permet tenir una idea aproximada del ritme que seguí la immigració francesa a Cervera durant els segles XVI $\mathrm{i}$ XVII.

Si aquest ritme d'entrada de francesos durant els dos segles esmentats, basat en la informació oferta pels capítols matrimonials, l'apliquem a la divisió cronològica que havem establert anteriorment, tindrem els percentatges següents:

- La crítica situació en què quedà Cervera després de la guerra dels Segadors resta reflectida en una acta del Consell municipal, redactada l'any 1652, segons la qual les autoritats cerverines es veieren obligades a fer-se càrec de moltes cases de la vila, ja que es trobaven deshabitades per haver-se mort tota la familia i no existir hereus. Per a més informació: Josep Maria Llober PORTElla, La "Taula de Canvi" de Cervera y su entorno socio-económico (1599-1715), Lleida, Instituto de Estudios Ilerdenses, 1985, p. 82-104. 
La immigració francesa a Cervera segons els capitols matrimonials...

I) 1501-1550. Període de 50 anys en què entrà el 13,91\% del total dels marits francesos enregistrats.

II) 1551-1630. Comprèn 80 anys i dóna un $74,44 \%$.

III) 1631-1700. Són 70 anys, amb un 11,65\%.

Com a complement, podem dir que, enfront de la nombrosa arribada de francesos, les persones procedents d'altres regnes són molt poques, com mostra el mateix quadre 1. Pel que fa a aquells dos segles XVI i XVII, els marits no catalans ni francesos localitzats són els següents: 9 aragonesos, 4 castellans, 3 navarresos, 2 borgonyons, 2 napolitans, 1 biscaí i 1 italià. Conjuntament, representen el $0,57 \%$ del total.

\section{PROCEDÈNCIA DELS IMMIGRANTS}

Els capitols matrimonials que permeten identificar el nuvi com a francès, acostumen a indicar, a més de la menció del regne de França, la població i el bisbat de procedència del futur marit. En alguns casos, però, només es fa referència al bisbat $i$, en altres, solament al regne d'origen. En conseqüència, en el moment d'establir la procedència dels immigrants francesos - quadre número $2 \mathrm{i}$ mapes - ho havem fet per bisbats? Aquestes demarcacions, a la vegada, són agrupades en quatre zones geogràfiques ${ }^{8}$ : "Pirineus i Pre-pirineus", "Llenguadoc i conca de la Garona», «Terres altes i massissos», i «Altres bisbats». Finalment, una columa inclou aquells casos en els quals no consta 0 no ha pogut ser identificat el bisbat d'origen.

En el quadre número 3 podem observar la procedència dels immigrants francesos a partir d'una distribució en zones geogràfiques.

7 És de justícia fer constar el nostre agraïment al professor Enric Moreu-Rey per les seves orientacions bibliogràfiques sobre toponímia.

8 En el moment de formar aquests agrupaments, havem seguit el criteri establert a l'excel.lent obra: J. NADAL, i E. GIRALT, La population catalane..., p. 67-75. 
Gairebé la meitat dels que estipularen matrimoni procedien dels Pirineus i Pre-pirineus i, dintre d'aquesta zona, fou el bisbat de Comenge el que donà la immensa majoria dels desplaçats. En segon terme queden les diòcesis de Coserans i Rieux, i en un lloc inferior la resta de bisbats.

El Llenguadoc i la conca de la Garona proporcionaren prop del $16 \%$ dels francesos que es casaren a Cervera, però més de la meitat d'ells procedien del bisbat d'Auch.

El percentatge de francesos que arribaren de la zona de les terres altes y massissos fou del 21. La diòcesi que en proporcionà un major nombre va ser Llemotges, seguida de Caors, Tula i la resta.

Poc nombrosa degué ser la immigració que arribà d'altres bisbats no compresos en la divisió anterior. Almenys l'escassetat de nuvis - un per diòcesi- així ho fa creure.

Finalment, de prop d'un $16 \%$ dels francesos que concerten capitulacions matrimonials a Cervera no en sabem el bisbat d'origen, encara que consta que procedien del regne de França.

\section{CAUSES DE LA MIGRACIÓ}

És evident que perquè es pogués produir aquesta migració, important tant per la seva llarga durada com per l'elevat nombre de desplaçats que en determinats periodes ocasionà, com posen en evidència les xifres que havem indicat, hagué d'existir, simultàniament, unes circumstàncies adverses que obligaven a abandonar el territori francès a un determinat nombre dels seus habitants i una situació favorable a la, aleshores, vila de Cervera i les seves rodalies - com també en bona part de la resta de Catalunya - que feia que molts dels nouvinguts s'hi establissin.

Quant a les causes que produiren l'emigració originada a l'àmbit geogràfic dels Pirineus i Pre-pirineus, Llenguadoc i conca de la Garona, i terres altes i massissos, se'n poden detectar de comunes, la principal de les quals fóra les guerres de religió que especialment durant la segona 
meitat del segle XVı afectaren a aquests territoris, i altres més particulars, que a continuació comentem breument ${ }^{9}$.

A la zona dels Pirineus i Pre-pirineus existia un fort desequilibri entre l'alta densitat de població i l'escassetat de recursos econòmics, la qual cosa es notava especialment a la diòcesi de Comenge; l'oferta de treball no podia absorbir la gran concentració humana, part de la qual es veia forçada a l'emigració. Aquesta situació s'agreujà amb les lluites per qüestions de fe que afectaren notablement, a més del bisbat de Comenge, el de Coserans i els de Pàmies i Rieux. Les xifres del quadre número 2 són ben significatives pel que fa a aquests bisbats.

Al Llenguadoc i conca de la Garona la situació era molt diferent de la dels Pirineus i Pre-pirineus. No hi havia ni un excedent demogràfic important ni una situació de treball agrícola desfavorable. En aquesta zona les causes de l'emigració sembla que s'ha d'atribuir, en general, a les guerres de religió que empobriren el país i produiren un abandonament del camp per part dels pagesos. Amb tot, com indiquen els quadres números 2 i 3 , les xifres corresponents al Llenguadoc i conca de la Garona són molt més baixes que les que es refereixen a la zona dels Pirineus $\mathrm{i}$ Pre-pirineus $\mathrm{i}$, fins $\mathrm{i}$ tot, que les concernents al territori més llunyà de les terres altes i massissos.

Finalment, a les dites terres altes i massissos, hom pot distingir la part del nord, on la pobresa del país -el pasturatge era una de les activitats més esteses- $i$ el temperament aventurer dels habitants els empenyaria a l'emigració, i la part del sud, que arruinada al final del segle xv per les lluites i les pestes, no oferiria massa atractiu als naturals de la terra, especialment quan la situació s'agreujà amb les guerres de religió. Llemotges al nord i Caors al sud foren els bisbats que, segons el quadre número 2 , es veieren més afectats per la sortida d'emigrants.

Pel que fa a les causes que facilitaren la immigració dels francesos a Cervera i poblets de la rodalia, cal tenir en compte que, passades les turbulències de la guerra contra Joan II, la població s'anà recuperant, especialment a partir del regnat de Ferran el Catòlic. A la segona meitat del segle XVI i durant el XVII, la vila es veié immersa en una situació de transformació que comportà una major dedicació a les activitats artesa-

a Una visió molt detallada de les causes de l'emigració a: J. NADAL, i E. GiraLT, La population catalane..., p. 97-114. 
nes i comercials. Amb tot, el sector agrícola i ramader continuà sent important.

El bon emplaçament de la vila -era reial-, situada en una zona de gran comerç, en la qual es compraven els cereals de les comarques de la Segarra i l'Urgell per a ser transportats a Barcelona, i lloc de pas dels ramats de bestiar destinats al consum de carn i de corrues d'animals de labor que, procedents de la muntanya, es traslladaven a les comarques tarragonines, explica que les activitats mercantils fossin abundants.

Tant fou així, que l'any 1599 Cervera aconseguí autorització reial per a poder elegir «burgesos» i la concessió del privilegi d'erecció d'una Taula de Canvi ${ }^{10}$.

Aquesta situació de Cervera, població de base agrícola però amb un bon sector de menestrals, es veu reflectida en la professió dels immigrants francesos que s'estableixen en la població i rodalies: gairebé tots ells són pagesos o artesans.

La població cerverina acollí sense problemes aquesta arribada constant de francesos. Es fa difícil trobar termes despectius envers ells en la documentació local de l'època ${ }^{11} \mathrm{i}$ els que es casaren ho feren, generalment, amb donzelles del país $i$, més rarament, amb alguna vídua. Si fa no fa, com els nascuts a la contrada.

L'estat de guerra entre Espanya i França o, millor dit, les actuacions de la Junta de Represàlies, creada a Madrid l'any 1635, segurament degué frenar l'entrada de francesos, com sembla mostrar-ho el quadre número 1. Amb tot, els naturals del regne de França establerts a Cervera i rodalies poc es degueren veure perjudicats, ja que si bé s'aplicà l'embargament de béns, como ho demostra la documentació de l'època, sembla que la mesura només recaigué sobre els immigrants solters ${ }^{12}$. La

10 Sobre aquesta institució: Josep Maria Llobet Portella, La «Taula de Canvi» de Cervera y su entorno socio-económico (1599-1715), Lleida, Instituto de Estudios llerdenses, 1985.

1 L'any 1631, els capitans de la confraria de Santa Magdalena, basant-se en una informació sobre la desinsaculació dels francesos de totes les confraries i col.legis barcelonins, proposaren al Consell municipal cerverí que es prengués la mateixa mesura quant a les confraries locals. El Consell de la vila va desestimà la proposta. AHCC, Fons Municipal, Consells de Vint i-quatrena, 1605-1634, f. 17 (1631).

12 J. NADAL, I E. Giralt, La population catalane..., p. 50. 
La immigració francesa a Cervera segons els capítols matrimonials...

mateixa documentació precisa que les represàlies afectaven «los béns de francesos vassalls del rey de França» ${ }^{13}$.

\section{ACTIVITAT LABORAL DELS IMMIGRANTS}

Tal com indica el quadre número 4, dels 266 francesos que consten com a casats a Cervera, més d'una tercera part eren pagesos. Si hi afegim els dos llauradors i el pastor, veurem que gairebé el $40 \%$ d'aquests marits es dedicaven a activitats relacionades amb el camp.

Pel que fa als artesans, és de remarcar la gran quantitat d'oficis que trobem representats entre els nouvinguts. En nombre, destaquen els teixidors de lli.

També hi figura un bon grup d'aquelles persones que es dedicaven a treballs relacionats amb la construcció d'edificis: hi podem veure 22 mestres de cases i 6 pedrapiquers. Per altra banda, no és despreciable el nombre de moliners, ja que arriben a 13.

D'aquest col.lectiu d'immigrants, 18 consten com a treballadors, sense més precisió, i 10 no tenen ofici conegut.

Les activitats laborals dels francesos que s'establiren a Cervera i rodalies durant els segles XVI i XVII, semblen confirmar, en línies generals, la visió que teníem d'aquesta població pel que fa al període esmentat: una vila amb repartiment equilibrat entre les activitats agrícoles $i$ les artesanals.

\section{CONCLUSIONS}

A partir de les dades $\mathrm{i}$ comentaris de les pàgines anteriors, podem formular les conclusions següents:

13 AHCC, Fons Notarial, Guissona, 14, Jaume Guardiola, Manual, 1636-1637, bossa de les cobertes. 
- Pel que fa al ritme d'entrada dels immigrants francesos que es casaren a Cervera durant els segles XVI i XVII, podem distingir tres períodes cronològics de desigual intensitat:

l) 1501-1550. Cinquanta anys amb un 13,91\% dels nouvinguts. Els marits francesos representen el $5,44 \%$ del total dels homes que s'amulleraren a Cervera en aquell mig segle.

II) 1551-1630. Vuitanta anys amb un 74,44\%. Els marits francesos constitueixen el $9,55 \%$ del total dels homes que s'uniren en matrimoni, a la vila, en aquest segon període.

III) 1631-1700. Setanta anys amb un 11,65\%. Els marits francesos són el 2,87\% del total dels homes que celebraren casament, a la població, durant els setanta anys esmentats.

- Enfront del 6,94\% de marits francesos que tenim pel període de dos segles, els procedents d'altres regnes hispànics o europeus només arriben, en conjunt, al $0,57 \%$ del total.

- La zona geogràfica que aportà més immigrants francesos fou els Pirineus i Pre-pirineus, amb gairebé la meitat del total, mentre que el bisbat que oferí l'emigració més elevada va ser el de Comenge.

- Les causes de l'emigració francesa, considerades globalment, es poden resumir en dos: desequilibri entre la densitat de població $i$ els recursos econòmics, i malestar originat per les guerres de religió.

- Paral.lelament, els motius de la immigració cerverina, també vistos de forma general, serien un desenrotllament de les ocupacions artesanals i comercials, i un manteniment de les tradicionals activitats agrícoles.

- Els nouvinguts sembla que s'integraren sense problemes. Després d'habitar alguns anys a la població, anaven perden els senyals que indicaven llur origen.

- Gairebé el $40 \%$ dels francesos que es maridaren a Cervera es dedicaven a treballs relacionats amb l'explotació del camp. També és elevada la xifra d'aquells que exercien activitats artesanals. En canvi, fou relativament poc important el nombre de francesos sense un ofici conegut que s'establiren a la població. 
La immigració francesa a Cervera segons els capítols matrimonials...

QUADRE 1

PROCEDĖNCIA DELS IMMIGRANTS SEGONS ELS CAPITOLS MATRIMONIALS

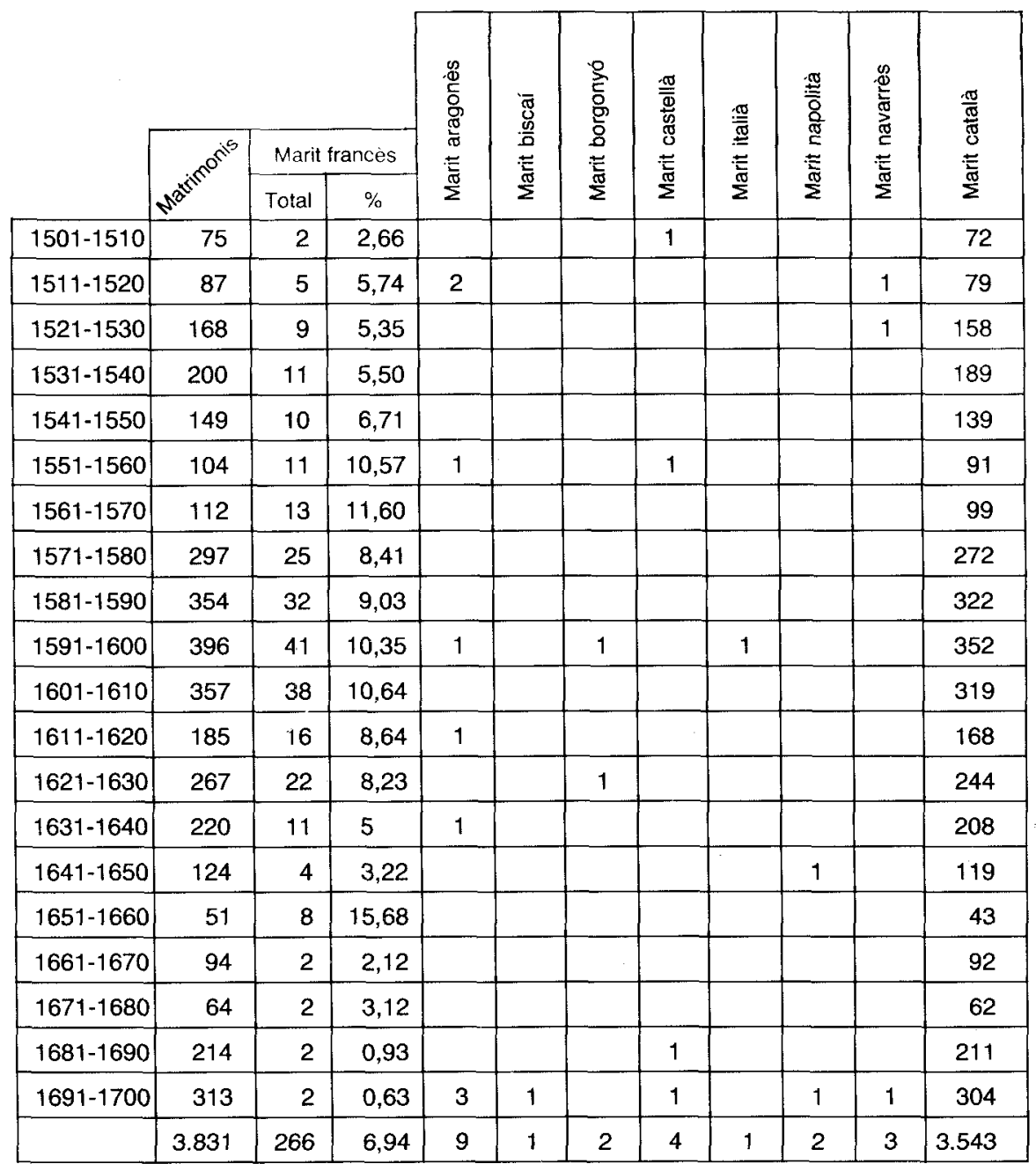


QUADRE 2

PROCEDĖNCIA DELS IMMIGRANTS FRANCESOS PER BISBATS SEGONS ELS CAPÍTOLS MATRIMONIALS

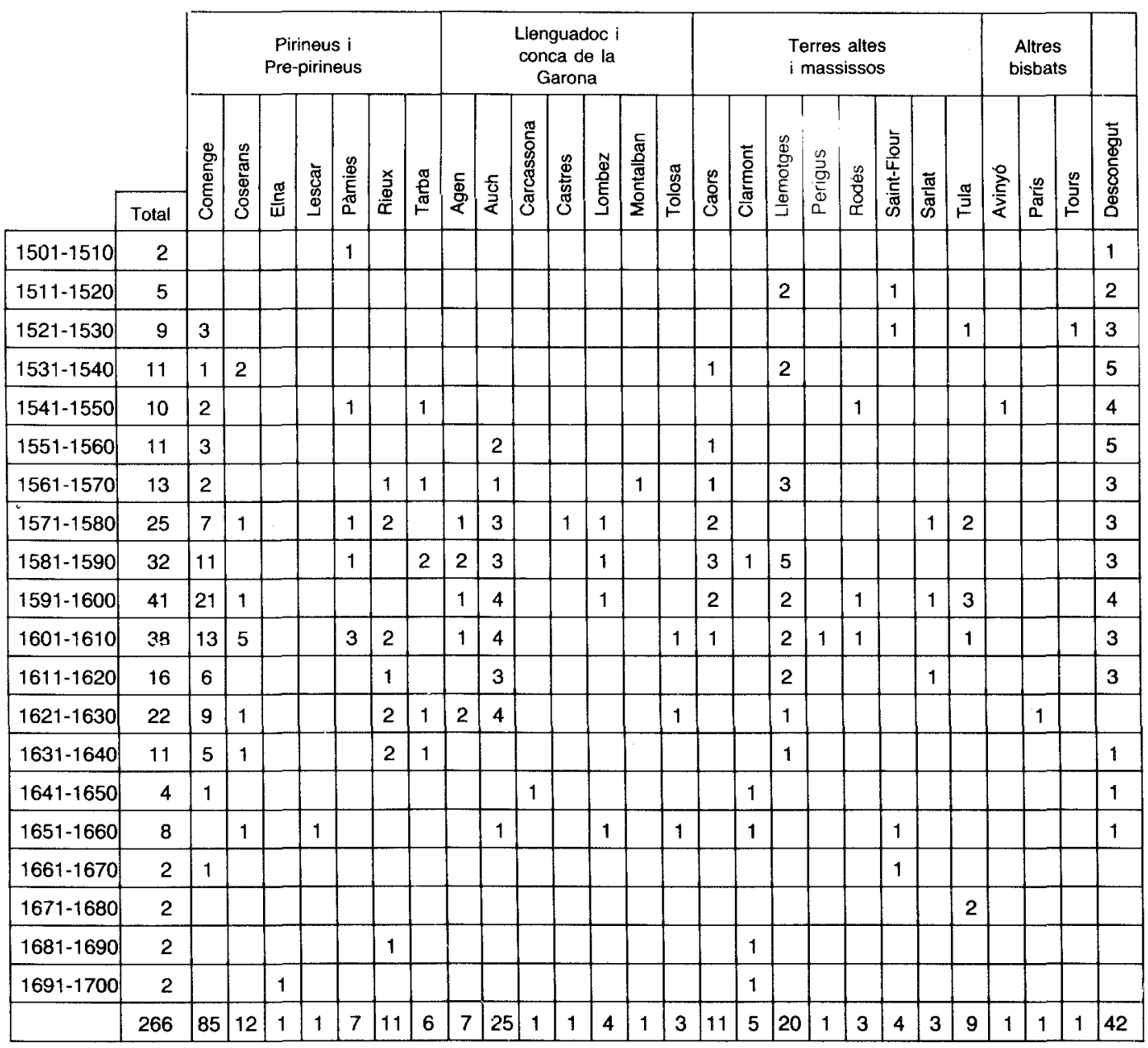


QUADRE 3

PROCEDÈNCIA DELS IMMIGRANTS FRANCESOS PER ZONES GEOGRÀFIQUES SEGONS ELS CAPITOLS MATRIMONIALS

\begin{tabular}{|l|c|c|}
\cline { 2 - 3 } \multicolumn{1}{c|}{} & Total & $\%$ \\
\hline Pirineus i Pre-pirineus & 123 & 46,24 \\
\hline Llenguadoc i conca de la Garona & 42 & 15,79 \\
\hline Terres altes i massissos & 56 & 21,05 \\
\hline Altres bisbats & 3 & 1,13 \\
\hline Bisbat desconegut & 42 & 15,79 \\
\hline & 266 & 100,00 \\
\hline
\end{tabular}


JOSEP MARÍA LLOBET PORTELLA

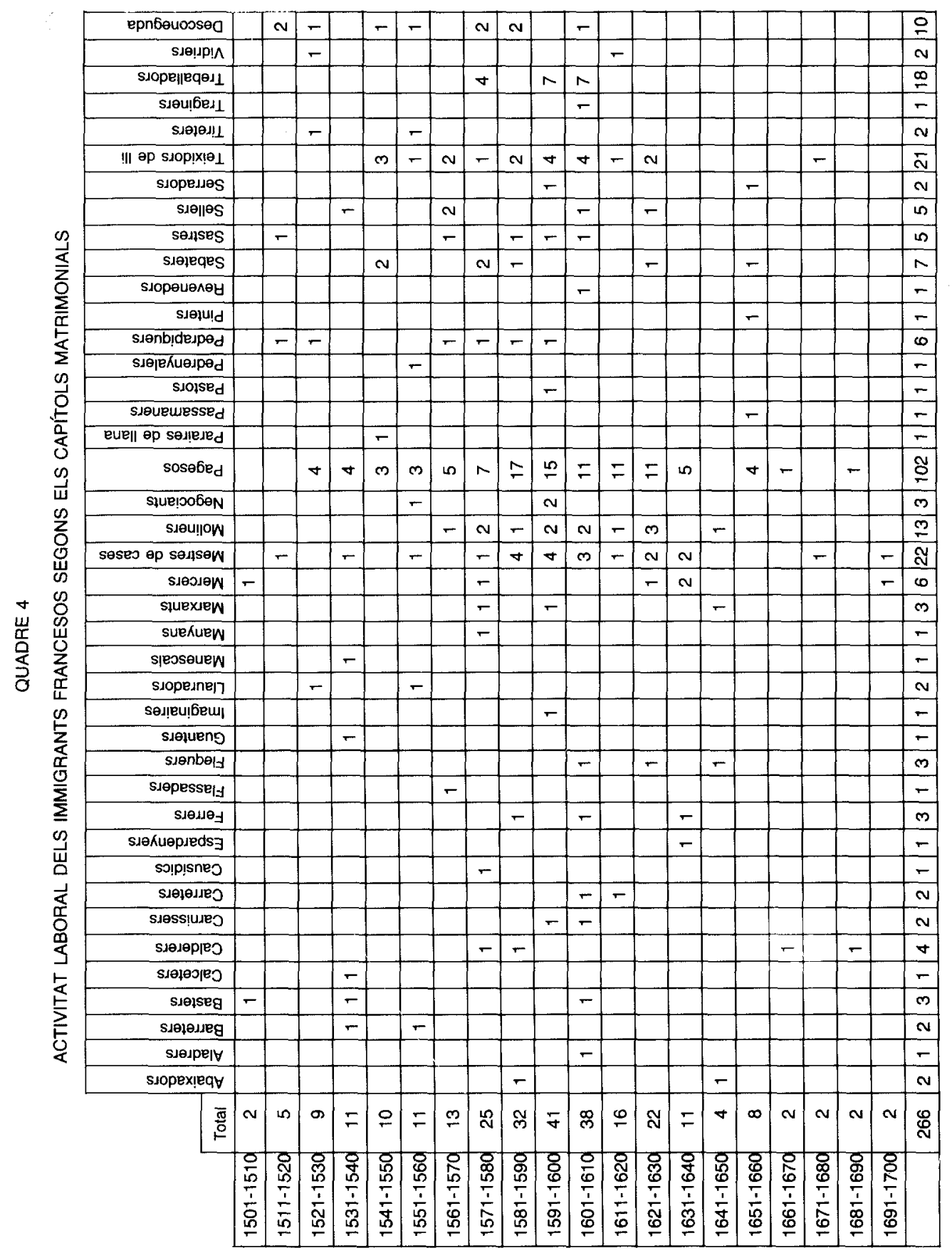


La immigració francesa a Cervera segons els capitols matrimonials...

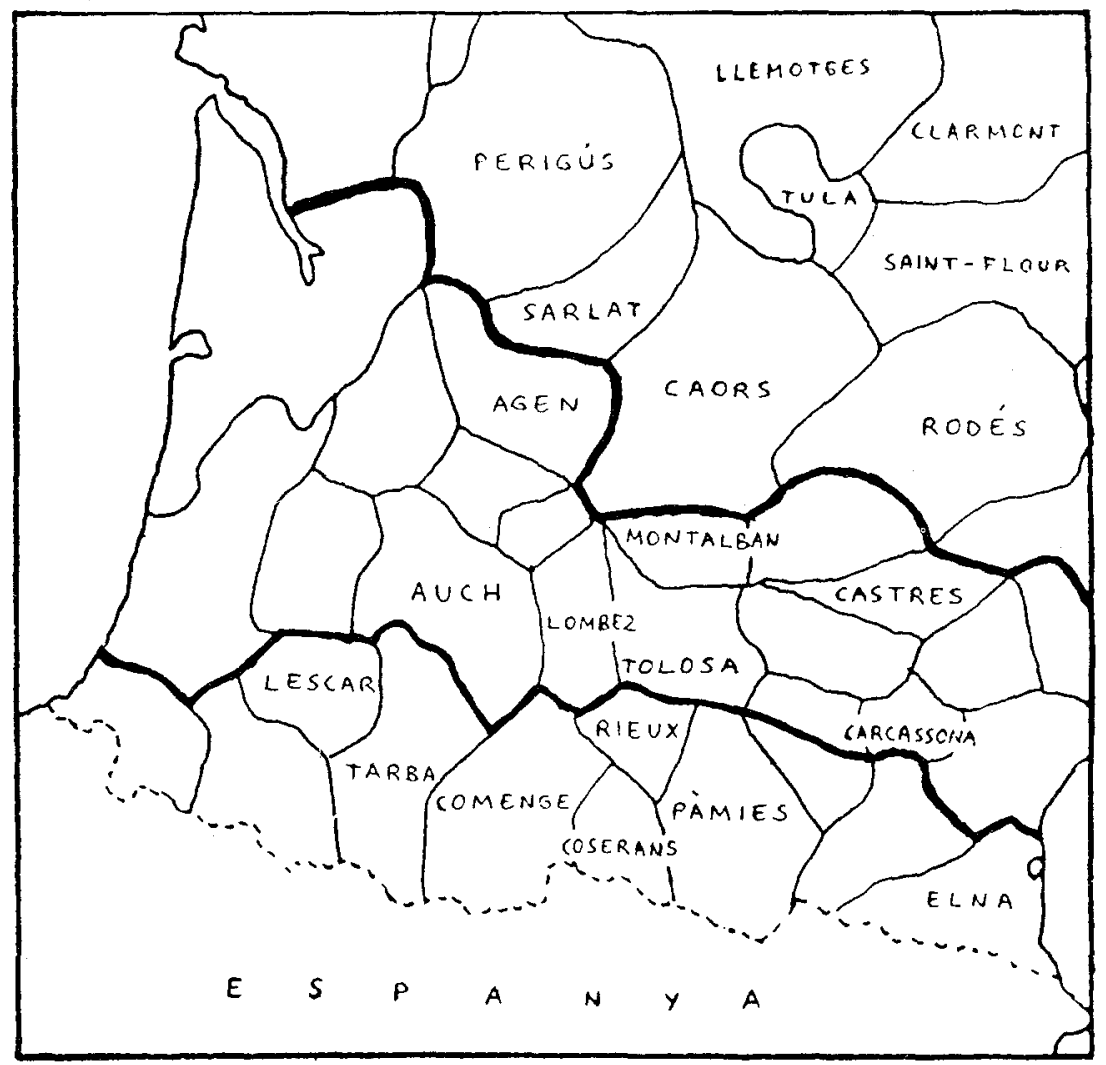

Bisbats d'origen dels immigrants francesos segons el Quadre 2. 


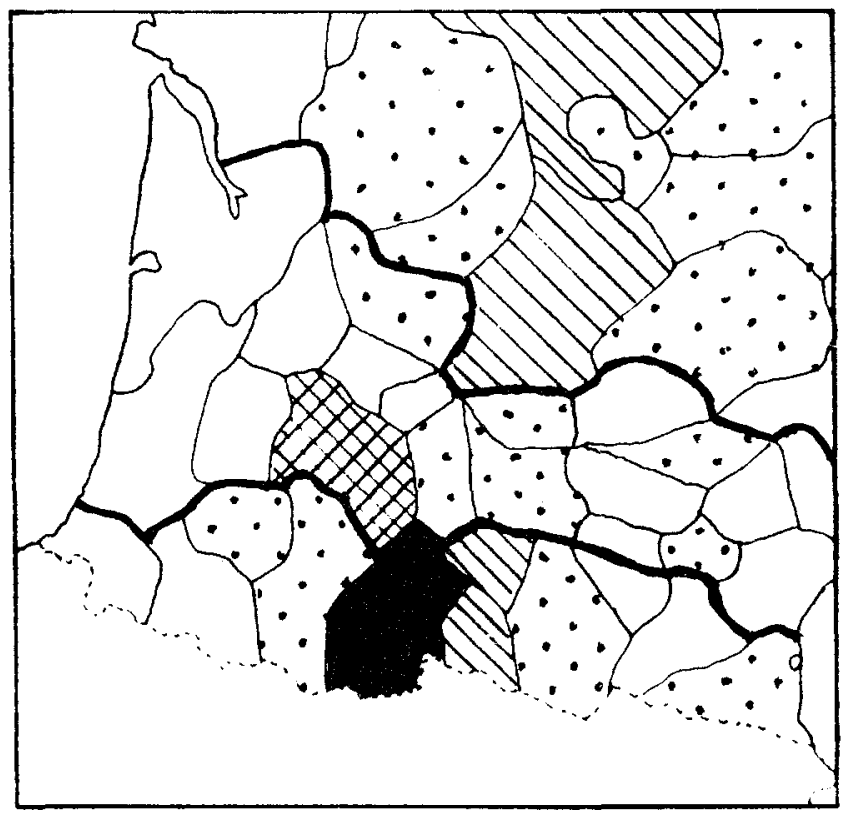

$1501-1700$
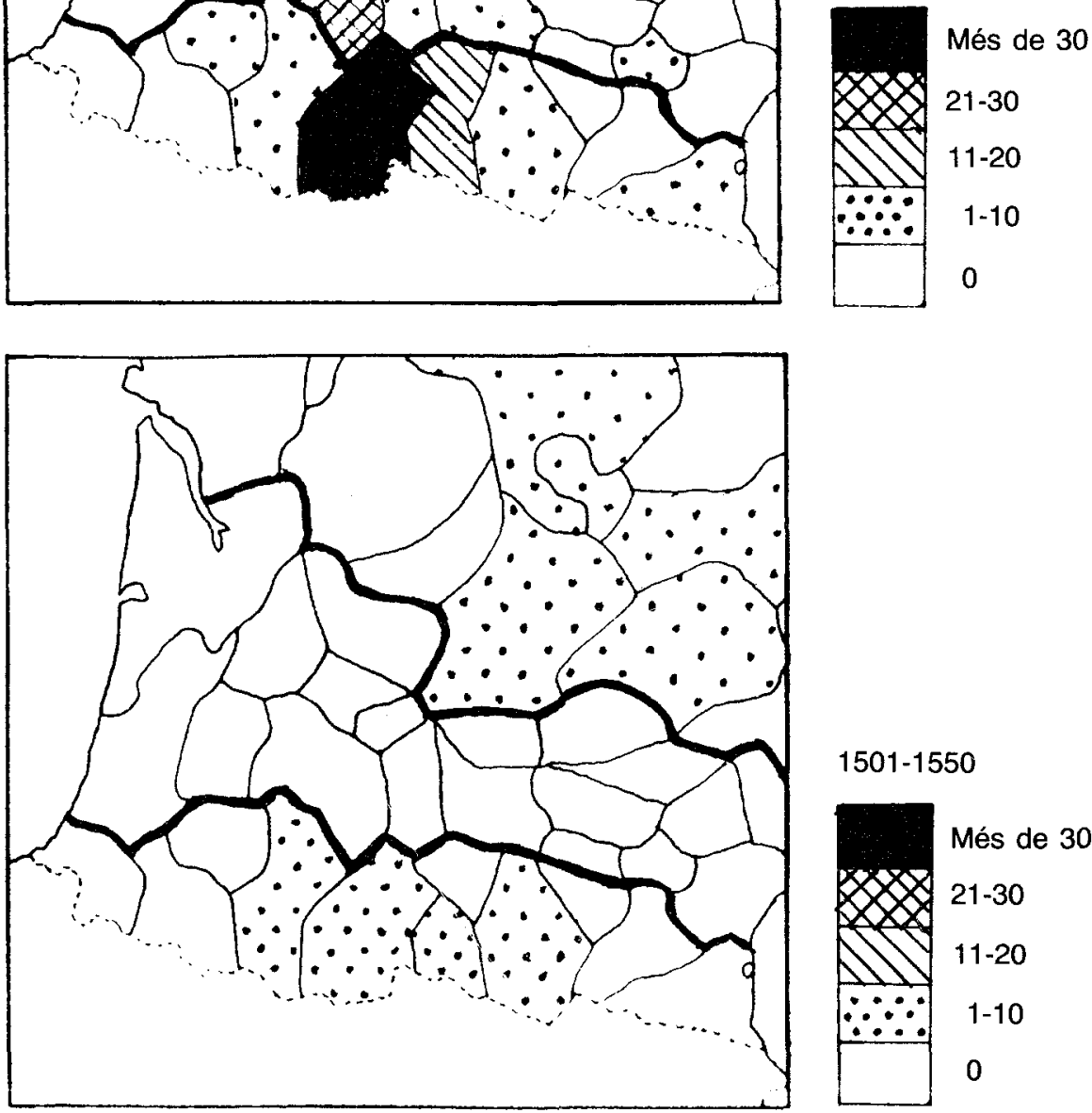

$1501-1550$

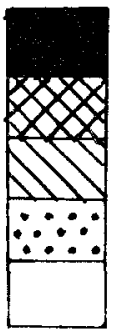

Més de 30

$21-30$

$11-20$

$1-10$

0

Nombre de morits francesos d'acord amb el bisbat d'origen segons el Quadre 2. 
La immigració francesa a Cervera segons els capitols matrimonials...

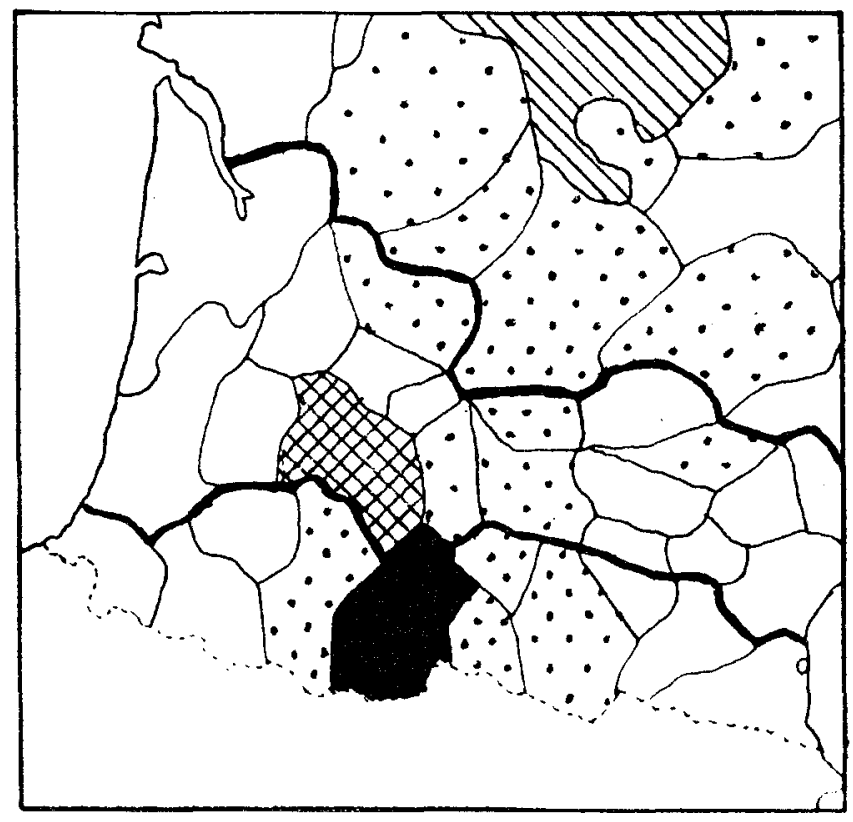

$1551-1630$
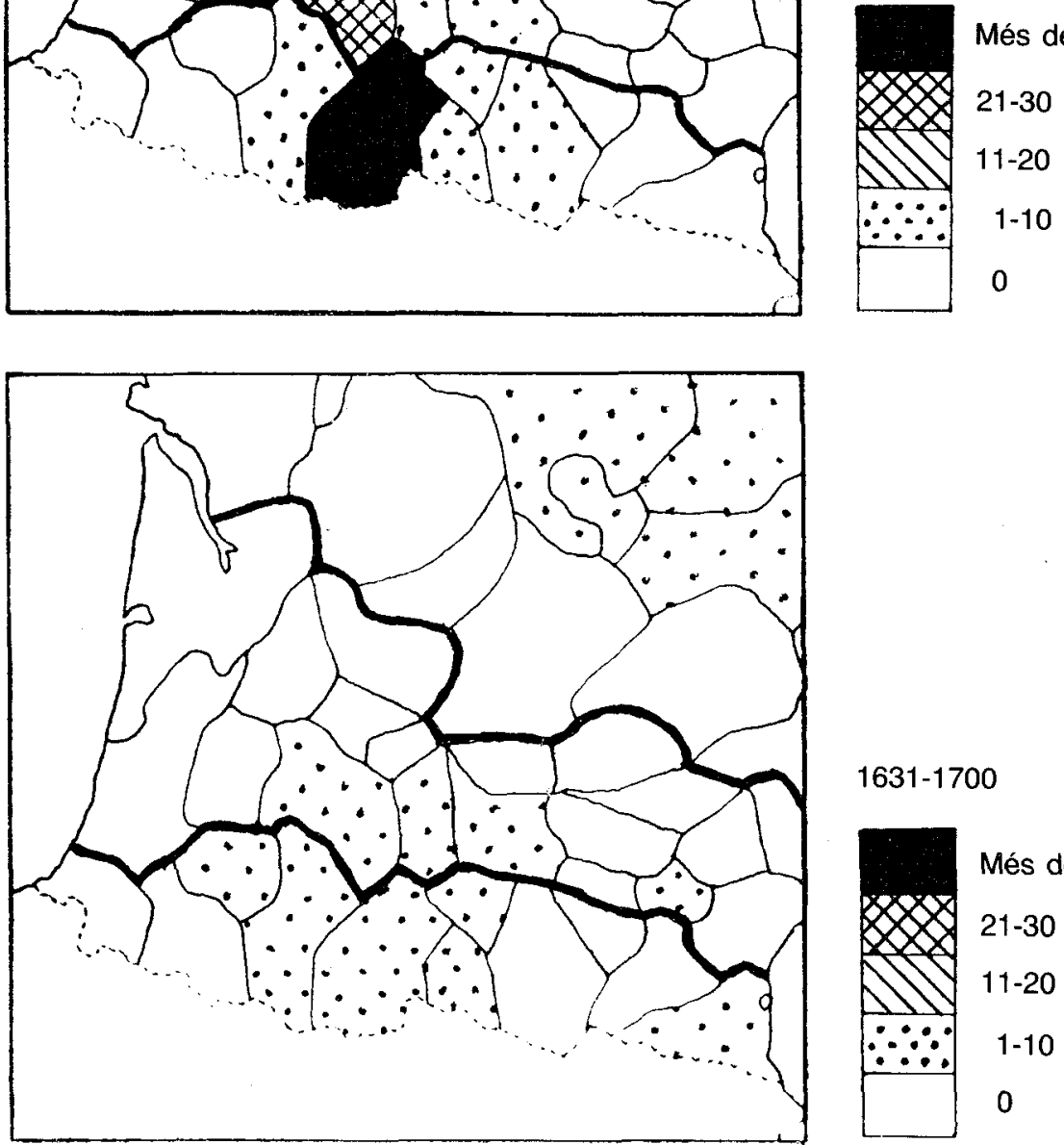

$1631-1700$

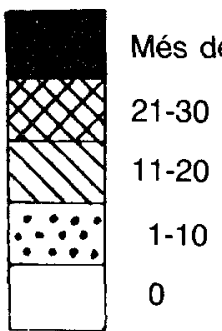

Nombre de morits francesos d'acord amb el bisbat d'origen segons el Quadre 2. 
